\title{
What the changes mean
}

\author{
Trish Groves
}

This is the second in a series of articles looking at the forthcoming changes to community care. The first article appeared on 5 December.
British Medical Journal, London WC1H 9JR

Trish Groves, assistant editor

$B M \mathcal{F} 1992 ; 305: 1489-90$
For many years now the British government has tried to replace institutional care with community care, particularly for people with chronic mental illness and learning disability (mental handicap). According to some researchers, this quest for "normalisation" has had too high a price, leaving many former patients untreated on our city streets. At the same time, many old people who might have coped in their own homes with adequate support have been sent to residential homes, at great expense to the tax payer. Whether or not the government believes that community care has failed thus far, it has listened to the criticisms and decided to overhaul its policy.

From next April new ways of delivering and funding care will be introduced. But, as David Browning of the Audit Commission has already pointed out (5 December, p 1415), April will probably bring evolution rather than revolution. Unlike the sweeping reforms that hospital staff and general practitioners have had to cope with in the past three years, the changes to community care are being introduced more gently.

\section{Time to think again}

In theory, gradual change should have allowed doctors time to think about and understand the community care reforms. Yet many doctors still find the plans confusing and nebulous, not least because many of the changes seem relevant only to social workers and health service managers. The jargon terms that pop up in community care literature"user," "mixed economy," "needs-led," and "ring fencing"-are off putting. And even the term "community care" seems ambiguous at times. Does it include community health services-those paramedical and nursing services such as occupational therapy, chiropody, and district nursing? And aren't these part of primary care?

When policy makers and planners talk about community care they are not usually referring to community health or primary care services. Instead, they mean practical and social services for people who need

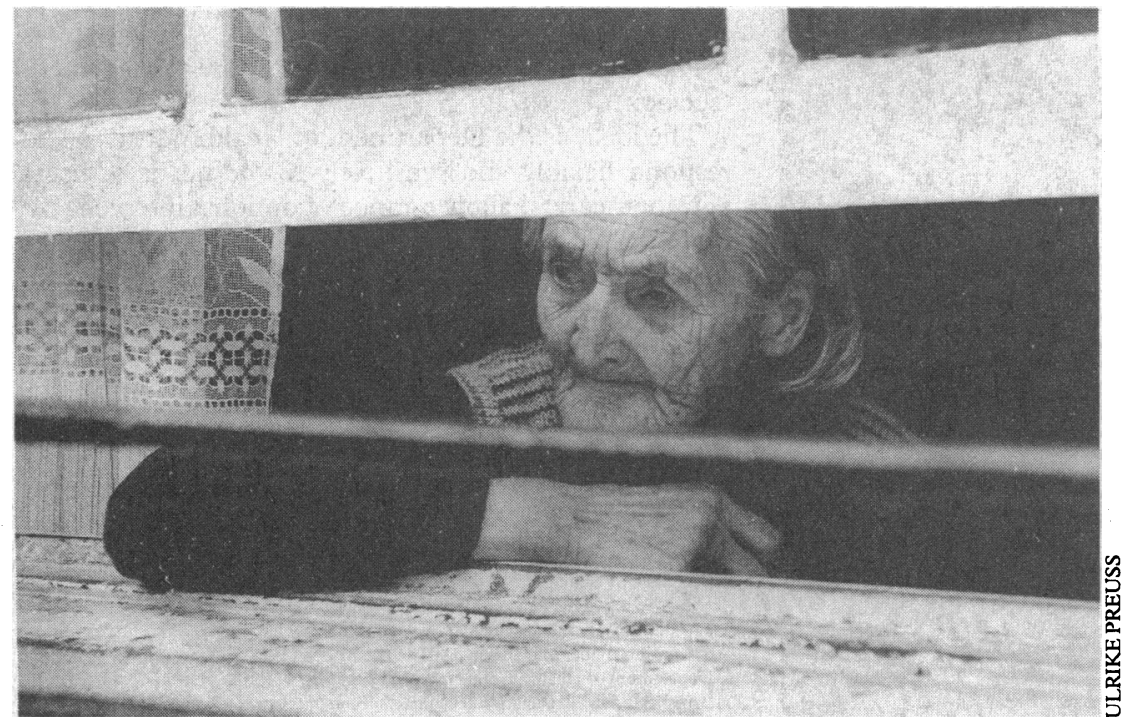

Waiting for the revolution

\section{Countdown to community care}

April 1991

- Inspection and complaints procedures set up

- Grants for severe mental illness and drug and alcohol problems introduced

April 1992

- Community care plans published by local authorities after consulting health authorities, family health services authorities, and other agencies

- Care programmes introduced for severely mentally ill people

December 1992

- Health authorities (health boards in Scotland) draw up plans on good practice in discharging patients from hospital

April 1993

- Local authorities take lead responsibility and receive funding for strategic purchasing and care management

- Care management starts

- User and carers get more say in planning, assessment, and choice of services, and can complain more easily

- General practitioners get regular information about local care services, make prompt and effective referrals for care, and provide basic clinical information to care managers (with patients' permission)

- Community care plans and services are monitored by local inspection units and the Social Services Inspectorate.

These details apply in England, Wales, and Scotland. In Northern Ireland health and social services already work together in boards which will fund and organise care management after April 1993.

help with daily life but are not so disabled that they have to live in large institutions and hospitals. Most people who need such help can be fitted conveniently into discrete groups: they are frail and old, or have chronic psychiatric problems, or have mental or physical handicaps.

Some critics argue, however, that lumping disadvantaged people into labelled groups and assuming that they all have roughly the same needs is patronising and stigmatising. Trying to make people match existing services can also lead to failure to provide the right kind or amount of care. When too little care is given, people's needs are not met. When too much is given (for instance, when elderly patients are sent unnecessarily to residential homes), people's rights are ignored and scarce time and money are wasted.

\section{Radical change required}

One of the first critiques of this "service led" community care system came from the Audit Commission. The commission is an independent body that was established nearly 10 years ago to monitor the 
economics, efficiency, and effectiveness of public services. In 1986 it reviewed community care and found much of it to be seriously uneconomic, ineffcient, and ineffective.' Following this the government decided to set up its own review and asked Sir Roy Griffiths, deputy chairman of both the NHS policy board and the Sainsbury's supermarket chain, to execute it.

The Griffiths report, published in 1988, suggested radical changes to community care. ${ }^{2}$ Local authorities should act as brokers of care by assessing people's needs and buying them packages of services, said $\mathrm{Sir}$ Roy. Clearly earmarked or "ring fenced" funds to do this should be raised by stopping social security payments for residential care and giving the money to local authorities. Care packages should include services run by the independent (private and voluntary) sector as well as statutory social services, drawing together a haphazard collection of services to make an accessible and usable "mixed economy" of care. Finally, a minister for community care should be appointed to coordinate the various government departments-including health, social security, education, and environment - that play a part in delivering care.

The government agreed to implement most of Sir Roy's recommendations, ${ }^{34}$ and, after several delays and setbacks, ${ }^{5}$ set next April as the full starting date. There will be no minister for community care, however, and funds will be earmarked only for a three year transitional period. ${ }^{\circ}$

\section{What will happen when}

Some of the changes have happened already (see previous page). Mechanisms for planning, inspecting, and complaining about the new system have been introduced over the past two years.

In addition, to quell mounting fears about psychiatric community care, three measures directly affecting people with mental health problems have begun. The first two measures are special grants for which local authorities and voluntary organisations must bid. One is designed to help the voluntary sector (organisations such as Turning Point and Alcohol Concern) to

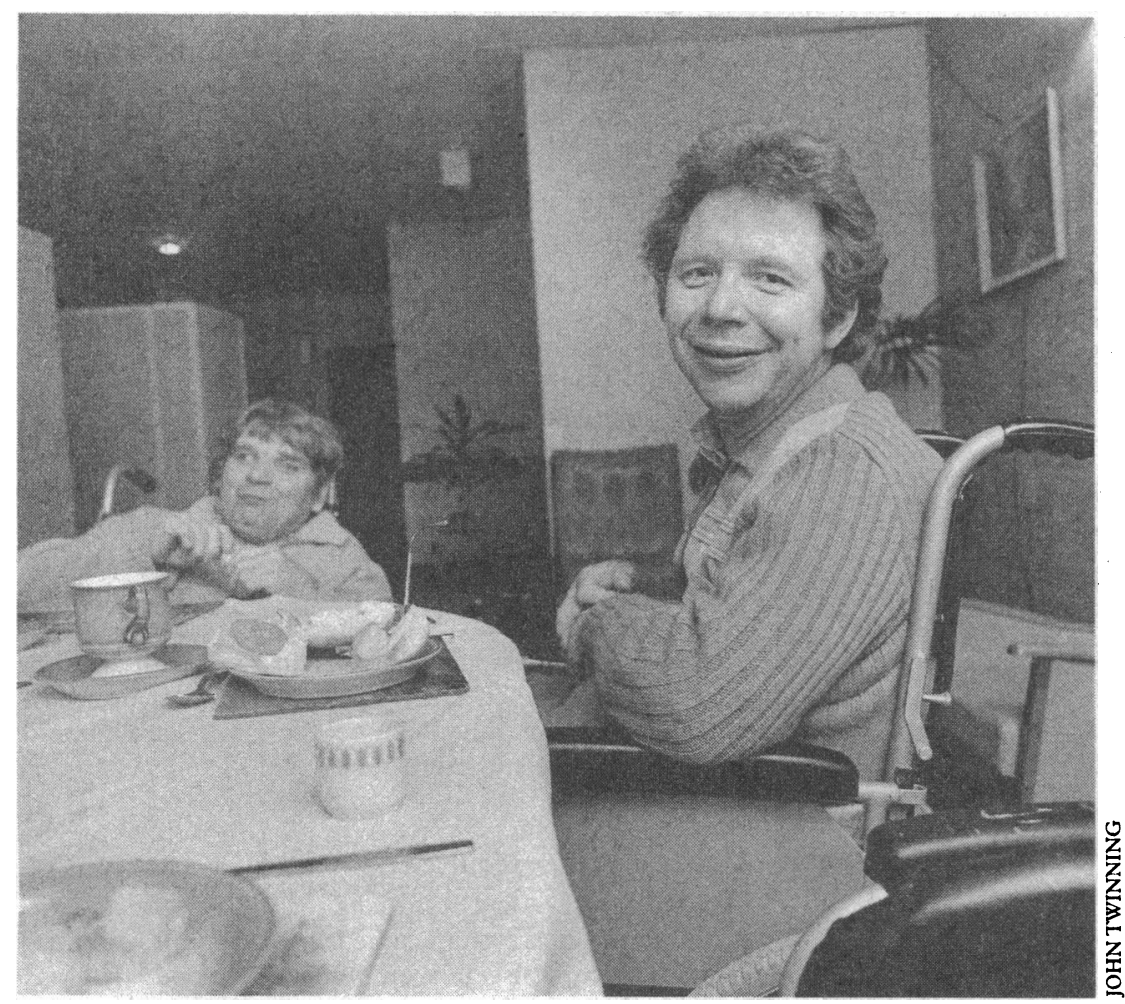

Users of community care will get more say if all goes to plan

\section{Managing care}

Sarah Jarvis is a 72 year old widow who has spent the past three months in hospital after having a stroke. Despite some residual weakness on the left side she can just about walk with a Zimmer frame. She is eager to get home and her consultant agrees that hospital care is no longer necessary.

Mrs Jarvis's medical team has referred her to the local social services department and she has been allocated a care manager, Judy Peters. She hasn't met Judy, but she knows how to contact her if any problems arise. Several people have come to the hospital to find out what help she will need after discharge. Her key worker, Jim Grant, has taken her back home with an occupational therapist and a home help organiser to assess what aids she might need.

Mrs Jarvis's general practitioner, Dr Harley, already knows that discharge is imminent and has a fair idea of the help being organised, because the ward sister has phoned the practice nurse to explain the plan. In addition Dr Harley has spoken to Judy Peters, the care manager, about Mrs Jarvis's general health (with permission, of course) and has asked a district nurse to provide help with bathing.

As soon as some ramps and safety rails have been fitted around the house, Mrs Jarvis will be discharged. Because she won't be able to get out and about on her own, she has been offered a place at the local Age Concern day centre twice a week, plus a lift there from a volunteer driver.

develop services for people with drug and alcohol problems. The other is meant to fund new services for people with severe mental illness. The third measure is the introduction of care programmes. Since last April health authorities have had to ensure that patients with severe mental illness are offered comprehensive and well documented programmes of care on discharge from hospital. Patients must be allocated named key workers and care must be supervised and reviewed continuously by consultant psychiatrists.

\section{Care management}

Next April sees the arrival of the most radical changes and of a new breed of professional. Care managers (who will probably have trained and worked as social workers, home care organisers, community nurses, or other practitioners) are roughly the social services equivalent of fundholding general practitioners. Unlike general practitioners, however, care managers will not actually deliver care themselves. Rather, they will organise multidisciplinary assessments for people needing help and will then try to arrange exactly what is needed. A case vignette is probably the easiest way to illustrate care management (see box)

The idea, as the Department of Health puts it, is "to respond flexibly and sensitively to the needs of users and their carers; allow a range of options; intervene no more than is necessary to foster independence; prevent deterioration; and concentrate on those with the greatest needs." The idea is good. But many commentators, including the $\mathrm{BMA}^{7}$ and the Audit Commission, ${ }^{8}$ still worry that putting it into practice will prove too difficult.

1 Audit Commission. Making a reality of community care. London: HMSO, 1986. 2 Griffiths R. Community care: agenda for action. London: HMSO, 1988.

Secretaries of State for Health, Social Security, Wales, and Scotland. Caring for people: community care in the next decade and beyond. London: HMSO, 1989.

4 Secretary of State for Northern Ireland. People first, community care in Northerm Ireland in the 1990 L. London: HMSO, 1990.

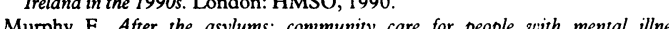

London: Faber and Faber, 1991.

6 Department of Health. Caring for people newsletter 1992;11.

7 British Medical Association. Priorities for community care. London: BMA, 1992.

8 Audit Commission. The community care revolution: personal social services and community care. London: HMSO, 1992. 